\title{
Application of Task-driven Teaching Method in High Vocational Computer Teaching
}

\author{
Zhongqiao Sun, Yonggang Wu \\ Jingzhou Institute of Technology, Jingzhou Hubei, 434020, China
}

Keywords: Task-driven teaching method, Higher vocational college, Computer, teaching.

\begin{abstract}
The application of task-driven teaching method in high vocational computer teaching can cultivate students' autonomous learning ability and problem solving ability and let them gain knowledge in practice. It has been widely applied in classroom teaching. As social demand for high-quality computer talents continues to rise, a large number of higher vocational colleges set up computer specialty to cultivate more computer talents for the society. In talent training, the most important thing is to improve students' practical ability. Hence, task-driven teaching method owns very important practical value. This paper summarizes basic meaning of task-driven method, analyzes the possibility of introducing task-driven method in high vocational computer teaching, investigates the important value of task-driven teaching method in high vocational computer teaching, lists main principles of applying task-driven method in high vocational computer teaching and states the design steps of applying task-driven method in high vocational computer teaching.
\end{abstract}

\section{Introduction}

The main task of China's higher vocational education is to adapt to applied technical talents. The graduates should own favorable basic theoretical knowledge, solid technique application ability, broad scope of knowledge and quality. Computer specialty has high requirements for students' application ability and practical ability. Thus, teachers should pay attention to cultivating students' critical thinking and practical operation ability in teaching process. However, traditional high vocational computer teaching method is too old-fashioned, and often ignores the cultivation of students' critical thinking ability, thus restraining students' practical operation ability. Hence, the author considers task-driven method is very applicable to computer specialty teaching. It can improve students' ability to discover, analyze and solve problems in the process of solving specific tasks, and enhance students' subjective initiative for learning computer knowledge.

\section{Basic connotation of task-driven method}

In the task-driven method, the teacher arranges tasks for students, and then students autonomously complete relevant tasks to achieve knowledge teaching and learning. Based on task-driven method, teachers' teaching is no longer limited to verbal explanation and question asking in classroom. Interaction and communication between the teacher and students can improve greatly. Besides, through completing various tasks, students' learning initiative, teamwork ability and comprehensive quality can also improve. As the society has higher and higher requirements for comprehensive quality of high-level talents, it is extremely important to enhance ability cultivation of high vocational students.

\section{Possibility of introducing task-driven method in high vocational computer teaching}

High vocational computer courses pay attention to cultivating students' ability to grasp computer knowledge. The purpose is to promote students' practical operation ability. Knowledge structure of computer courses is complex, and the course systematicness is also prominent. The computer courses involve a large range. The relevance of some courses is not strong enough. Thus, it is very difficult for 
computer teachers to connect different contents in teaching process. After task-driven method is introduced, teachers can decompose teaching contents into small learning tasks, and they need not implement teaching according to the order of teaching materials so that knowledge relevance improves. Meanwhile, mutual connection among different courses and units can be reached. Thus, students can practically improve knowledge systematicness in this process, and students' ability to discover, analyze and solve problems. In addition, students can learn computer courses more confidently and actively. Therefore, it is very feasible to introduce task-driven method in high vocational computer teaching.

\section{Important value of task-driven teaching method in high vocational computer teaching}

Firstly, it can promote students' autonomous learning ability. Traditional computer teaching is mainly dominated by teachers. Generally speaking, teachers infuse much theoretical knowledge to students in classroom, and demonstrate the knowledge learned with the computer. The time left for students to operate the computer is quite little. Some teachers occupy classroom time and let students operate the computer in their spare time. In this way, classroom efficiency is impacted, and students' learning initiative also declines. Meanwhile, computer teaching effect is not ideal enough, either. When the task-driven method is applied in high vocational computer teaching, large learning task can be divided into multiple small tasks, and students can apply independent inquiry form to solve problems under teachers' rational guidance so as to improve learning enthusiasm and let students really become the subject of classroom teaching activity.

Secondly, it can promote students' comprehensive application ability. Based on task-driven method, task design and teaching have become an indivisible component. To solve practical tasks, students must deeply analyze the tasks, grasp the connotation of tasks and carry out practical operation according to the tasks assigned. In this way, they can better complete various tasks. So, the application of task-driven method in high vocational computer teaching can not just cultivate students' ability to solve practical tasks, but also train their ability to analyze problems so as to drive them to better develop.

Thirdly, it can enhance students' innovation consciousness. Because teachers would impart specific knowledge points to students in the previous teaching, this may easily cause students to lack their own thinking space, which is adverse to development of their innovative thinking. After task-based approach is introduced, and students grasp relevant knowledge, tasks may be applied to guide the development direction for students. In this way, students can discover problems in problem solving process, carry out innovation learning based on relevant teaching content and resolve practical problems through their own efforts. This is very beneficial to improve students' innovative thinking ability.

\section{Main principles of applying task-driven method in high vocational computer teaching}

Firstly, suitability principle. When teachers of higher vocational colleges apply task-driven method, they should rationally apply it according to teaching contents, knowledge points and students' practical conditions, and rationally choose knowledge points to teach in accordance with knowledge point distribution in the teaching material. The teaching tasks designed by teachers should be closely related to knowledge points, and cannot be designed at will. Meanwhile, teachers should carry out group instruction according to students' features, and let students cooperate and interact with each other.

Secondly, interestingness principle. Only the interesting teaching tasks can greatly attract students, and then the teaching effect of task-driven method can improve. So, teachers of high vocational colleges should comprehensively cognize this principle when implementing task design, and conduct targeted task design in accordance with students' age characteristics.

Thirdly, relevance principle. The arrangement of computer textbook knowledge system owns great systematicness and relevance. Thus, computer teachers of high vocational colleges should well 
grasp the relevance between tasks and knowledge and among tasks when arranging tasks. The application of this method aims to better implement teaching activity. Meanwhile, teaching quality should continue to improve. Teachers of high vocational colleges should implement design task well under the precondition of routine courses, pay attention to scientific connection of each task and knowledge point and control well logic and consistency among tasks. Besides, they should well grasp the relevance between theoretical knowledge and practical operation, and let the task not just cover new knowledge and new skills, but also cover some old knowledge and skills.

\section{Design steps for applying task-driven method in high vocational computer teaching}

Firstly, to confirm task objective. Before the implementation of task-driven teaching method, the specific task objective should be first confirmed. In other words, the key points and difficult points in the teaching process should be confirmed to make sure the task chosen can combine new and old knowledge points. Then, knowledge points can be overall combined in the classroom teaching task. This can make sure students not just learn new knowledge when completing the task, but also comprehensively consolidate the old knowledge so as to overall apply new and old knowledge. Teachers also should scientifically set tasks according to students' features and learning needs, and let them finish various learning tasks in the relaxing and harmonious atmosphere.

Secondly, to conduct task setting. When task setting is implemented, computer teachers of high vocational colleges should decompose the task according to teaching objective. In other words, teachers should integrate specific knowledge points in each learning task according to the learning objective and let the decomposed tasks overall cover all knowledge points in the objective. The main operation process is to set the integral task according to the teaching content. The total task should be decomposed into multiple small tasks in accordance with the specific knowledge points. Meanwhile, the key and difficult points should be decomposed, and combined in the sub-tasks. In this way, the difficulty in completing various tasks can decrease. Besides, rational guidance of teachers can practically help students grasp important knowledge points as soon as possible, and help them establish confidence, improve learning enthusiasm and then enhance learning efficiency. During task setting, teachers should fully exert learners' enthusiasm, guide students to carry out deep thinking, actively find out problems, learn and discuss the problems. With active guidance of teachers, students' potential can be better stimulated, and their practical ability can be well trained.

Thirdly, to analyze teaching task. After computer teachers of high vocational colleges arrange the teaching task, they should arrange students to systematically analyze the learning task, help students confirm learning objective and direction, actively organize students to know how to overall apply knowledge pints in the specific learning task through detailed discussions. For example, when explaining how to apply PowerPoint software to make courseware, teachers should actively organize students to discuss knowledge points involved in courseware making after students clearly know various learning tasks. Then, teachers should gradually guide students to subdivide various tasks according to the existing knowledge. For example, what materials should be chosen? How to design PPT interface and overall style? How to design PPT transition form? How to design user-defined animation and voice? Teachers should let students conduct autonomous exploration and discussion of the above questions so as to continuously deepen their understanding of knowledge points, diverge students' thinking and help them innovatively apply knowledge points when completing learning tasks.

Fourthly, to complete teaching task. One of the most important links to apply task-driven teaching method in high vocational computer courses is to how to complete the teaching task. Teachers of high vocational colleges should organize students to learn and discuss learning tasks, guide them to conduct autonomous exploration, discover and analyze problems when completing the task as well as solve specific problems by applying the knowledge learned. Meanwhile, teachers should guide students to carry out practical operation and continuously improve their ability of computer practice. In the process of carefully completing tasks, computer teachers may give students rational guidance, but should not excessively interfere in students' thinking habit. Teachers should give students space 
and chance to comprehensively show their ability, guide them to indicate their views and express their opinions actively so as to help students expand their thinking and improve their creative ability.

\section{Conclusion}

In general, the application of task-driven method in high vocational computer teaching can better promote their learning initiative. Flexibility and exploration property of this method very conform to features of high vocational computer majors, and this method can practically improve current teaching mode and enhance teaching effect. Computer teachers should specify various task objectives during applying task-driven method, carry out detailed analysis of teaching task according to the objective and penetrate knowledge points in the learning task. When students completing the task, teachers should give students rational guidance, and help students deepen their understanding of knowledge points and improve their ability to apply computer knowledge so as to enhance students' comprehensive computer application ability.

\section{References}

[1] Chen Xiaoqin, Exploration on Application of "Task-driven Method" in High Vocational Computer Teaching, Xuezi (New Education Concept), 2014 (11).

[2] Zhang Min, Li Jun, Cultivation of Computational Thinking in Task-driven Teaching Method, China Education Technique and Equipment, 2015 (12).

[3] Cao Zhengqiao, Study on Application of “Task-driven Method” in High Vocational Computer Teaching, Intelligence, 2015 (20).

[4] Wang Xiaofei, Exploration on Application of "Task-driven Method" in High Vocational Computer Teaching, Industry \& Science Tribune, 2016 (8).

[5] Xiong Wei, Application of “Task-driven Method” in High Vocational Computer Teaching, Digital Communication World, 2016 (9). 